See discussions, stats, and author profiles for this publication at: https://www.researchgate.net/publication/305817180

\title{
An experimental investigation on the machining characteristics of Nimonic 75 using uncoated and TiAlN coated tungsten carbide micro-end mills
}

Article in CIRP Journal of Manufacturing Science and Technology · January 2017 DOI: $10.1016 / j . c i r p j .2016 .07 .005$

\section{CITATIONS}

39

6 authors, including:

Niharika Swain

National Aerospace Laboratories

7 PUBLICATIONS 160 CITATIONS

SEE PROFILE

Praveen Kumar

Lnipe

16 PUBLICATIONS 184 CITATIONS

SEE PROFILE

Some of the authors of this publication are also working on these related projects:

Graphene by HF-CVD technique View project

Project Spectrally selective solar absorber coating View project
Vijay Venkatesh

The Ohio State University

11 PUBLICATIONS 123 CITATIONS

SEE PROFILE

Gorre Srinivas

Vasavi College of Engineering

34 PUBLICATIONS 350 CITATIONS

SEE PROFILE 


\title{
An experimental investigation on the machining characteristics of Nimonic 75 using uncoated and TiAlN coated tungsten carbide micro-end mills
}

\author{
Niharika Swain ${ }^{\text {a }}$, Vijay Venkatesh ${ }^{\mathrm{a}, 1}$, Praveen Kumar ${ }^{\mathrm{a}}, \mathrm{G}$. Srinivas ${ }^{\mathrm{a}}$, S. Ravishankar ${ }^{\mathrm{b}}$, \\ Harish C. Barshilia ${ }^{\text {a,* }}$ \\ a Nanomaterials Research Laboratory, Surface Engineering Division, CSIR-National Aerospace Laboratories, Post Bag 1779, Bangalore 560017, India \\ ${ }^{\mathrm{b}}$ Aircraft Prototype Manufacturing Facility, CSIR-National Aerospace Laboratories, Post Bag 1779, Bangalore 560017, India
}

A R T I C L E I N F O

Article history:

Available online 2 August 2016

\section{Keywords:}

Micro-milling

Nickel superalloys

Tool wear

Slot geometry

Burr formation

\begin{abstract}
A B S T R A C T
We report the machining characteristics and machinability of a nickel based superalloy in this study. A micro-milling operation is loaded on Nimonic 75 using uncoated and TiAlN coated tungsten carbide micro-end mills. A full factorial design of experiments was devised to optimize the machining conditions to reduce the flank wear on the tool surface. The optimized machining conditions for uncoated microtools were found to be a cutting speed $\left(v_{\mathrm{c}}\right)$ of $13 \mathrm{~m} / \mathrm{min}$ and a feed rate $\left(f_{\mathrm{z}}\right)$ of $6 \mathrm{~mm} / \mathrm{min}$. Following this, the tools were coated with TiAlN using a semi-industrial four-cathode reactive pulsed direct current unbalanced magnetron sputtering system. Further experiments were then performed using these optimized machining conditions using both uncoated and TiAlN coated micro-tools in order to ascertain the tool wear and surface integrity. The change in geometry of the machined slot was estimated based on the variation in tool radius of the micro-end mill with progression of the operation. A direct comparison was made between the results observed using both uncoated and TiAlN coated tungsten carbide to illustrate the effect of the nanocomposite TiAlN coating. It was seen that TiAlN coated micro-tools exhibited a superior performance as compared to the uncoated ones with respect to tool life and microburr formation.
\end{abstract}

(c) 2016 CIRP.

\section{Introduction}

The recent advances in the manufacturing sector have necessitated the miniaturization of machine tools. Working with these miniaturized tools often results in low power consumption, high productivity rate and smaller sizes of work stations [1]. Due to these inherent advantages, micro-machining techniques such as micro-drilling, micro-milling, etc. have captured the attention of the scientific and industrial community. A particular application of these techniques is seen in the micro-cutting of 'difficult-tomachine' materials, which are widely employed in aerospace, automotive, medical and nuclear industries [1-3]. Commonly used nickel-based superalloys such as Inconel, Nimonic, Rene, etc. fall into this category. These superalloys find exclusive usage in the

\footnotetext{
* Corresponding author.

E-mail address: harish@nal.res.in (H.C. Barshilia).

1 Also at Department of Mechanical Engineering, Birla Institute of Technology \& Science, Pilani - Goa Campus, India.
}

turbine and combustor sections of aircraft engines due to their ability to exhibit high fracture strength, phase stability, increased resistance to wear and creep, etc. at elevated temperatures. However, on the contrary, poor thermal and mechanical properties of these superalloys limit their machinability, thus categorizing them as 'hard-to-cut' materials. Chief among these undesirable properties is the presence of high percentages of abrasive carbides, leading to accelerated wear on the tool surface [4,5]. It is also seen that these materials evince a phenomenon known as the 'workhardening effect', thus leading to high cutting forces and formation of burrs. Apart from this, it is observed that these superalloys adhere to the surface of the tool material, thus leading to galling and welding of the chip material on the workpiece. These characteristics cause low rates of material removal in the workpiece and high tool wear which subsequently lead to higher machining costs [6-8].

Micro-machining of these superalloys have been effectuated using both conventional and non-conventional machining techniques. Non-conventional techniques such as micro-electrical discharge machining (micro-EDM) and laser machining are mostly 
used to produce effusion cooling holes in the guide vanes of nozzles and turbine blades. However, both these techniques suffer from a few limitations which have propelled researchers to look at a few other methods. It has been reported that micro-EDM leads to high drilling costs at very low drilling speeds apart from disturbing material properties in the heat affected zone [9]. A severe damage to the back wall was observed when a laser technique was used to sculpt airfoil blades and fuel injector nozzles [10]. The aforementioned limitations have prompted the use of conventional machining techniques for drilling micro-holes or slotting microgrooves in these superalloys. The use of a conventional technique results in deeper holes with better straightness and roundness $[10,11]$. Apart from being independent of material properties, this technique also produces micro-holes and micro-slots with smoother surfaces. However, even these techniques suffer from a few drawbacks such as tool fracture caused by low rigidity of the micro-tool, higher tool wear on the flank surface, tool run out, etc. [12,13].

One particular way to overcome this difficulty is by using a hard material (such as cemented carbide) and depositing nanocomposite coatings such as TiN, TiAlN, TiAlSiN, etc. on its surface [1416]. Carbide micro-tools have been perennially used in the microcutting of these superalloys due to their high fracture toughness and resistance to thermal shock. Among the above mentioned coatings, it is revealed that depositing a nanocomposite coating of TiAlN leads to higher process efficiencies due to its higher oxidation resistance, hardness, and resistance to corrosion. In addition to this, it is possible to operate with higher cutting speeds when using micro-tools coated with TiAlN as compared to their uncoated counterparts due to the low thermal conductivity of TiAlN [17-19].

A quick survey of the literature indicates that micro-milling has largely been performed on Inconel 718 superalloy. Ucun et al. [17] investigated the influence of various coatings on tool wear in the micro-milling of Inconel 718 nickel superalloy. In another experiment, Ucun et al. [20] varied the operating parameters and reported their influence on surface roughness in the micro-end milling of Inconel 718. Kuram and Ozcelik [21] employed a design of experiments (DOE) strategy and set up a Taguchi $\mathrm{L}_{9}$ orthogonal array to report the influence of spindle speed, feed rate and depthof-cut on cutting forces and surface roughness in the micro-milling of Inconel 718. Ucun et al. [22] articulated on the machining characteristics of Inconel 718 superalloy using uncoated and DLC coated ultra-fine carbide micro-mills. It was seen that the use of a DLC coating significantly increased the surface finish and reduced the tool wear of the carbide micro-mills.

Nimonic, on the other hand has not captured the attention of researchers as compared to Inconel 718 . The literature indicates that there are no reports on the machining characteristics of Nimonic superalloys using uncoated and coated micro-tools. In order to bridge this gap, we have attempted a micro-milling operation on Nimonic 75 using uncoated and TiAlN-coated tungsten carbide micro-end mills under wet machining conditions. A nanocomposite TiAlN coating was deposited on tungsten carbide micro-end mills using a four-cathode reactive pulsed direct current unbalanced magnetron sputtering system. The performance of the uncoated and the TiAlN coated tungsten carbide micro-end mills was then ascertained by employing a full factorial experiment with cutting speed and feed rate as the control variables. The effects of these parameters on tool wear, burr formation, slot geometry and surface roughness were noted. Machining conditions which led to a high surface finish and productivity rate were identified and classified as optimum machining parameters. Further tests were performed with these optimized parameters using both uncoated and TiAlN coated micro-tools to determine the wear behaviour, surface integrity and flank wear. The results obtained from these experiments were then analyzed and elucidated to discern the effect of the TiAlN coating on the above mentioned output parameters.

\section{Experimental procedure and test conditions}

\section{Experimental details}

Micro-end milling tests were carried out on a homogenous Nimonic 75 rectangular block of dimensions $100 \mathrm{~mm} \times 30 \mathrm{~mm} \times$ $3 \mathrm{~mm}$. The nominal composition of the alloy is given in Table 1. On analysing its microstructure, it was found that the alloy consisted of a large number of HCP particles of $\mathrm{M}_{7} \mathrm{C}_{3}$ at the grain boundaries and a FCC solid-solution matrix of aluminium and titanium in the form of grain boundaries. The hardness of this workpiece was measured as 40-41 HRC.

The experiments were performed using a sub-micron grade tungsten carbide micro-end mill (SGS Solid Carbide Tools) having $10 \%$ wt. cobalt. The geometrical features of the micro-end mill are shown in Table 2. The grain size of the end-mill was measured and found to be between $500-900 \mathrm{~nm}$. Experimental tests were carried out using a CNC 3-axes vertical machining centre (VICTOR TAICHUNG) characterized by a maximum spindle speed of 50,000 RPM and a spindle power of $9 \mathrm{~kW}$. The tool run-out was measured after mounting the tool on the machine spindle using a Digital Dial Test Indicator (MITUTOYO) and found to be $1 \mu \mathrm{m}$. A spindle speed $(N)$ of 5175 RPM was used in this study. A water soluble semisynthetic oil (TASHCUT, S40), was mixed with water in a 1:20 ratio and used as the coolant with a set flow rate of $1.67 \mathrm{l} / \mathrm{min}$.

\section{Tool cleaning}

Prior to the deposition of the TiAlN coating, the high speed micro-end mills were cleaned in an ultrasonic agitator using commercial cleaning solutions to remove contaminants and adhered particulates. A mixture consisting of 3\% Rodaweg solution and $97 \%$ distilled water was used for this cleaning purpose. This was followed by rinsing the micro-mills in distilled water for 1 min. Ensuing this, a 1\% Galvex solution mixed with 99\% distilled water was used for further cleaning by placing the tool in an ultrasonic agitator for around 3-4 min. The aforesaid step was followed by rinsing the micro-tools in distilled water for a span of $1 \mathrm{~min}$ before placing them in an ultrasonic bath filled with distilled water for 2 min. Finally, the micro-end mills were dried with dry

Table 1

Composition of Nimonic 75 superalloy (\% wt).

\begin{tabular}{lllllll}
\hline Elements & $\mathrm{Cr}$ & $\mathrm{Al}$ & $\mathrm{Ti}$ & $\mathrm{Fe}$ & $\mathrm{Si}$ & $\mathrm{Ni}$ \\
\hline $\mathrm{W} \%$ & 18.0 & 1.0 & 1.0 & 3.0 & 1.0 & 76.0 \\
\hline
\end{tabular}

Table 2

Geometrical properties of the cutting tool used during cutting tests.

\begin{tabular}{ll}
\hline Parameters & Values \\
\hline Tool & Micro-end mill \\
Cutting diameter & $0.79 \mathrm{~mm}$ \\
No of flutes & 2 flute (square end) \\
Length of cut & $1.20 \mathrm{~mm}$ \\
Helix angle & $30^{\circ}$ \\
Rake angle & Positive \\
Overall length & $38 \mathrm{~mm}$ \\
Shank diameter & $3.17 \mathrm{~mm}$ \\
Edge radius & $5 \mu \mathrm{m}$ \\
Tolerance & $+0.00 /-0.01 \mathrm{~mm}$ \\
\hline
\end{tabular}


nitrogen before placing them in the vacuum chamber for the deposition of nanocomposite TiAlN coatings.

\section{Characterization of TiAlN coatings}

Nanostructured TiAlN coatings were deposited on the surface of the micro-end mill using a semi-industrial four cathode reactive direct current unbalanced magnetron sputtering system. The details of the sputtering technique are described elsewhere in the literature [18]. The thickness of the coating was measured using a Field Emission Scanning Electron Microscope (FESEM, SUPRA $40 \mathrm{VP}$, CARL ZEISS) and found to be $2 \mu \mathrm{m}$. The cutting edge radius of the micro-tool after TiAlN coating was found to be $5 \mu \mathrm{m}$. In order to ascertain the hardness of the nanolayered multi-layered TiAlN coating, hardness measurements were performed in a nanoindenter (CSM Instruments, load range $0.5-300 \mathrm{mN}$ ) at a load of $10 \mathrm{mN}$ using a Berkovich diamond indenter. Ten indentations were made on each sample and the values reported herein represent the average of the ten values. Further details on the nanoindentation measurements are expounded in a different article [18]. The surfaces of these coatings were then characterized using an atomic force microscope (AFM, BRUKER, SPMS Nanosystem) in non-contact mode with a tip radius of $15 \mathrm{~nm}$, in order to ascertain the surface roughness. The results revealed that tungsten carbide coated with TiAlN showed a surface roughness of $13 \mathrm{~nm}$ as compared to its uncoated counterpart which showed a surface roughness of $9 \mathrm{~nm}$.

\section{Machining parameters and experimental design}

Owing to the limited research in micro-machining of Nimonic 75 , preliminary experiments were conducted to optimize the cutting speed and feed rate, since it is well established that these are the most significant parameters affecting machining characteristics. In this regard, a full factorial design of experiments was performed by varying the cutting speed and feed rate according to industrial standards. The control variables for this experiment along with their respective values are shown in Table 3a. The depth-of-cut per pass in each run was kept constant at $120 \mu \mathrm{m}$ and grooves were slotted for a machining length of $100 \mathrm{~mm}$ using uncoated tungsten carbide micro-end mills. Fig. 1(a) shows the schematic diagram of a sample run of the experiment performed and a schematic illustration is shown in Fig. 1(b). The parameters of the run at which the lowest tool wear was observed were labelled as optimized machining parameters. The optimized machining parameters for this experiment were found to be a cutting speed of $13 \mathrm{~m} / \mathrm{min}$ and a feed rate of $6 \mathrm{~mm} / \mathrm{min}$. The tools were then coated with TiAlN and used along with uncoated tools to slot grooves for machining lengths of 30,150 and $300 \mathrm{~mm}$ using these optimized parameters. These coated tools were then observed under a FESEM in order to ascertain the influence of operating parameters and cutting length on tool wear. The percentage decrease in tool diameter was determined by observing the changes in the slot geometry using FESEM. In addition to this, the influence of operating conditions on surface roughness at different machining lengths were determined using a 3D surface profilometer (NANOMAP 500 LS AEP TECH) in contact mode with a stylus tip radius of $100 \mathrm{~nm}$. Finally, the formation of micro-burrs and burr height at different machining lengths was measured using FESEM and analyzed.

\section{Results and discussion}

The load vs. displacement curve was measured for a standard tungsten carbide and TiAlN coated tungsten carbide sample and the curves obtained from these tests are shown in Fig. 2(a).

Table 3a

Various factor levels for optimization in micro-milling process.

\begin{tabular}{|c|c|c|c|c|c|}
\hline Symbol & Control factor & Level - 1 & Level - 2 & Level - 3 & Level - 4 \\
\hline A & Cutting speed (m/min) & 11.0 & 13.0 & 15.0 & 18.0 \\
\hline B & Feed $(\mathrm{mm} / \mathrm{min})$ & 6.0 & 8.0 & 10.0 & - \\
\hline C & Test material & \multicolumn{4}{|c|}{ Nimonic alloy 75} \\
\hline $\mathrm{D}$ & Tool type & \multicolumn{4}{|c|}{ Uncoated WC } \\
\hline E & Machined length (mm) & \multicolumn{4}{|c|}{100} \\
\hline $\mathrm{F}$ & Coolant & \multicolumn{4}{|c|}{ Water soluble oil } \\
\hline G & End mill size $(\mu \mathrm{m})$ & \multicolumn{4}{|c|}{790} \\
\hline $\mathrm{H}$ & Depth of cut $(\mu \mathrm{m})$ & \multicolumn{4}{|c|}{120} \\
\hline
\end{tabular}

(a)

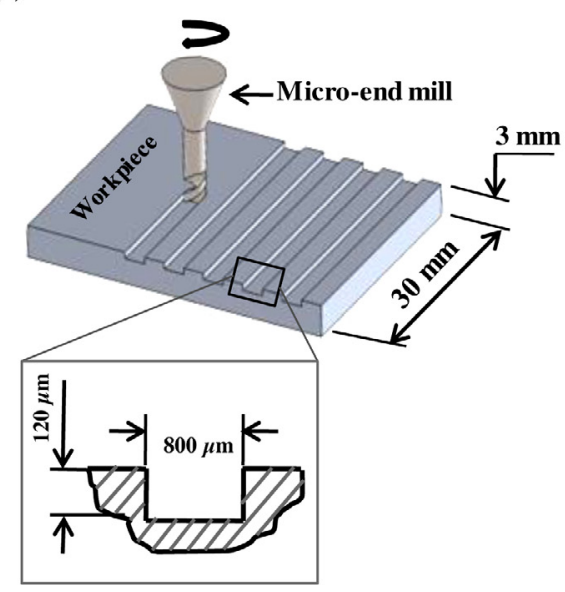

(b)

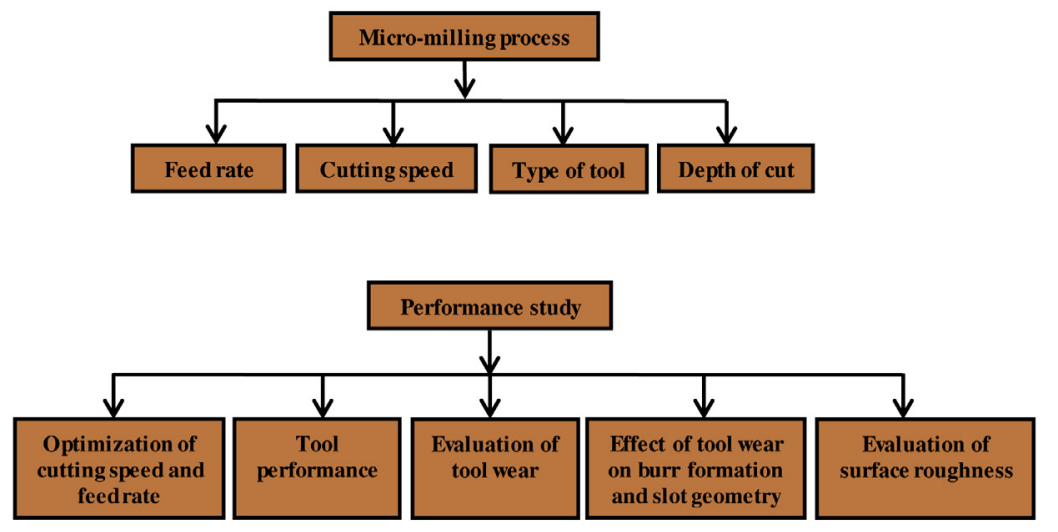

Fig. 1. (a) Schematic illustration and (b) layout of the micro-milling process. 

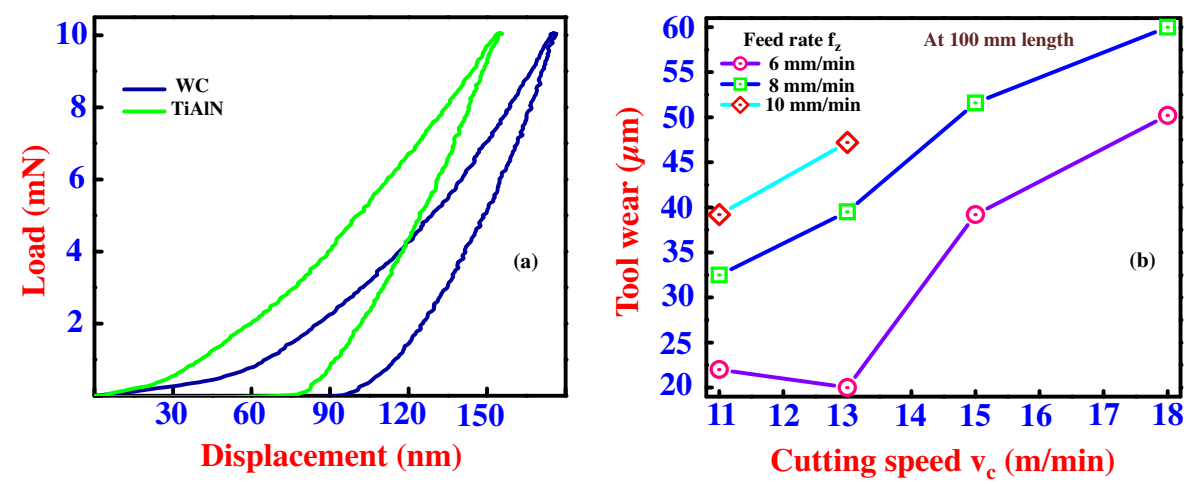

Fig. 2. (a) Load vs. displacement graphs for uncoated and TiAIN coated WC micro-end mill. (b) Variation in tool wear with different cutting speeds and feed rates.

Table 3b

Design of experiments with different levels of cutting speeds and feed rates.

\begin{tabular}{|c|c|c|c|c|}
\hline \multicolumn{5}{|c|}{ Test results } \\
\hline Exp. no. & Cutting speed $(\mathrm{A})(\mathrm{m} / \mathrm{min})$ & Feed rate $(B)(\mathrm{mm} / \mathrm{min})$ & Feed per tooth $(\mathrm{mm} / \mathrm{rev})$ & Tool flank wear $(\mu \mathrm{m})$ \\
\hline 1 & 11 & 6 & 0.00137 & 22.0 \\
\hline 2 & 13 & 8 & 0.00154 & 39.5 \\
\hline 3 & 15 & 10 & 0.00167 & Tool breaks \\
\hline 4 & 18 & 6 & 0.00083 & 50.2 \\
\hline 5 & 11 & 8 & 0.00183 & 32.5 \\
\hline 6 & 13 & 10 & 0.00193 & 47.2 \\
\hline 7 & 15 & 6 & 0.00100 & 39.2 \\
\hline 8 & 18 & 8 & 0.00116 & 60 \\
\hline 9 & 11 & 10 & 0.00228 & 39.2 \\
\hline 10 & 13 & 6 & 0.00115 & 20.0 \\
\hline 11 & 15 & 8 & 0.00133 & 51.6 \\
\hline 12 & 18 & 10 & 0.00139 & Tool breaks \\
\hline
\end{tabular}

The load was increased at a steady rate to the maximum value $(10 \mathrm{mN})$ and then decreased at the same rate back to zero. The hardness was then calculated from the Oliver-Pharr relation:

$H=\frac{P_{\max }}{A}$

where $P_{\max }$ is the peak indentation load and $A$ is the contact area. It was found that TiAlN coated tungsten carbide exhibited a hardness of $\sim 38 \mathrm{GPa}$ while the hardness of uncoated tungsten carbide was measured to be $\sim 24 \mathrm{GPa}$.

\section{Optimization of machining parameters}

Due to the poor machinability of nickel based superalloys that arise from their work hardening effect, it becomes imperative to operate at machining conditions which lead to an extended tool life. In order to achieve this purpose, a full factorial design of experiments was conducted with the objective of reducing the flank wear observed on the tool surface. The results of the flank wear for each run are tabulated in Table $3 \mathrm{~b}$ and the variations at different cutting speeds and feed rates for a constant machining length of $100 \mathrm{~mm}$ using uncoated tungsten carbide are plotted in Fig. 2(b). It may be noted that for each run, three experimental trials were conducted and the values reported herein represent the average of the three trials. The value for each trial was between $7 \%$ and $12 \%$ of the reported value. High wear on the flank surface could be inferred at high values of cutting speed as compared to high feed rates. Thus, it can be hypothesized that the cutting parameter plays a major influence in determining flank wear. It was also noticed that the uncoated tungsten carbide micro-end mill wears away rapidly at very high values of cutting speeds and feed rates. This can be ascribed to the poor thermal conductivity of Nimonic 75 which results in temperature gradient and pressure closer to the interface separating the workpiece and cutting tool. Additionally, poor surface finish was obtained when operating at low values of cutting speed and feed rate [23,24]. It was also observed that machining at higher cutting speeds $\left(v_{\mathrm{c}}=15 \mathrm{~m} / \mathrm{min}\right.$ and $\left.18 \mathrm{~m} / \mathrm{min}\right)$ and feed rates $\left(f_{z}=8 \mathrm{~mm} / \mathrm{min}\right.$ and $\left.10 \mathrm{~mm} / \mathrm{min}\right)$ leads to accelerated tool wear and finally tool breakage. Thus, from the above experiments, it was concluded that tool wear on the flank surface could be minimized when operating at a cutting speed of $13 \mathrm{~m} / \mathrm{min}$ and a feed rate of $6 \mathrm{~mm} / \mathrm{min}$. These optimized cutting parameters were hence recommended to further slot grooves for machining lengths of 30, 150 and $300 \mathrm{~mm}$ using both uncoated and TiAlN coated micro-mills.

\section{Performance evaluation of uncoated and TiAlN coated WC micro-end} mills

Slots of 30, 150 and $300 \mathrm{~mm}$ were machined using coated and uncoated tools at an optimized cutting speed of $13 \mathrm{~m} / \mathrm{min}$ and feed rate of $6 \mathrm{~mm} / \mathrm{min}$. The experiments revealed a steady increase in the tool wear of uncoated micro-tools up to a machining length of $300 \mathrm{~mm}$. The FESEM images captured for both uncoated and TiAlN coated micro-tools after machining a length of $300 \mathrm{~mm}$ are depicted in Fig. 3(a) and (b), respectively. It was observed that the cutting edge of the uncoated tool started exhibiting rapid wear upon machining a length of $150 \mathrm{~mm}$. Additionally, the sharpness of the tool started to decrease, perhaps due to the intense workload which increases the temperature at the tool-workpiece interface as discerned from Fig. 3(a) [25-27]. On the other hand, TiAlN coated micro-end mills showed appreciable resistance to wear even after machining a length of $300 \mathrm{~mm}$. The tip of the tool remained unaffected and there was no significant change in its radius. The cutting edge radius for the uncoated tool as shown in Fig. 3(a) was measured as $R_{1}: 21 \mu \mathrm{m}$ and $R_{2}: 19 \mu \mathrm{m}$ while that for a TiAlN coated tool was found to be $R_{3}: 9 \mu \mathrm{m}$ and $R_{4}: 11 \mu \mathrm{m}$. 


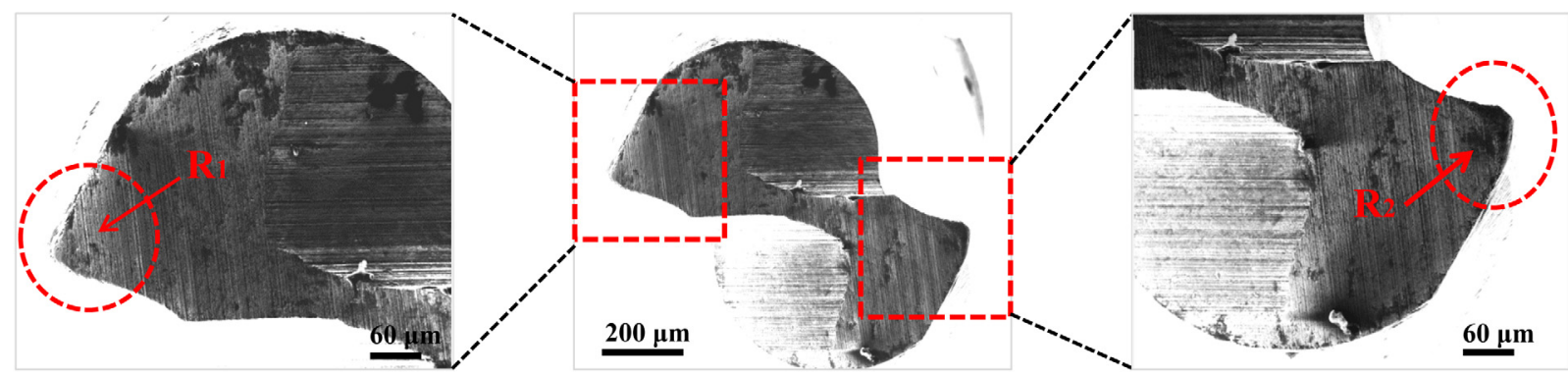

(a)

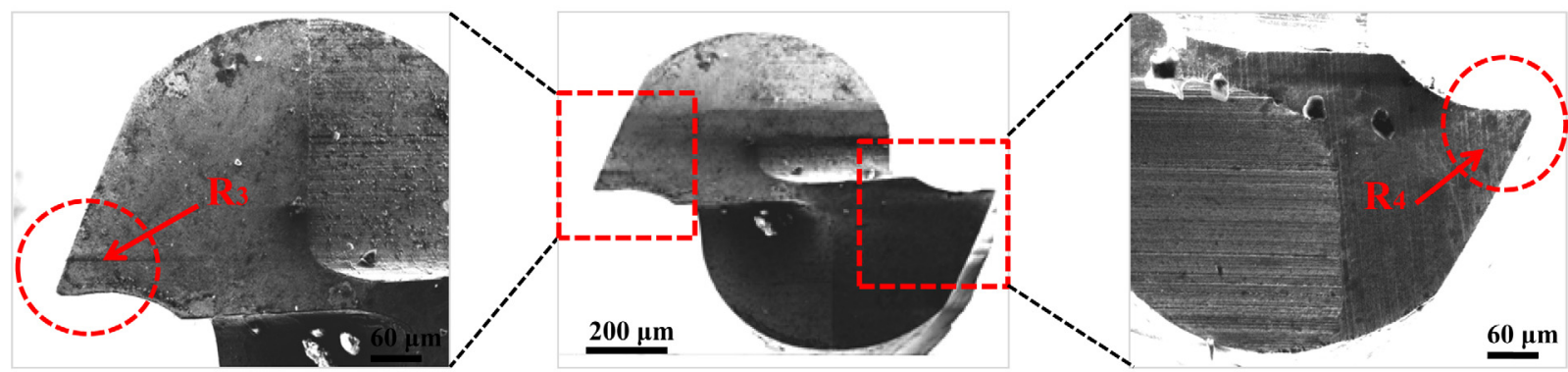

(b)

Fig. 3. Performance evaluation of: (a) uncoated and (b) TiAlN coated WC micro-end mill after slotting a length of $300 \mathrm{~mm}$.

\section{Evaluation of tool wear}

Fig. 4 illustrates the growth of tool wear with machining length for both TiAlN coated and uncoated micro-tools. It can be postulated from Fig. 4 that the stresses occurring over the coated micro-end mill is much less than that over the uncoated micro-end mill. The wear on the uncoated micro-tool was found to be greater than that of the TiAlN coated micro-tool by a factor of 1.97 and 1.67 at the end of $150 \mathrm{~mm}$ and $300 \mathrm{~mm}$ length of cut respectively. This can be attributed to the high hardness of the nanocomposite TiAlN coating along with the formation of a micro-thin oxide layer of $\mathrm{Al}_{2} \mathrm{O}_{3}$ as a result of the reaction between the TiAlN and the oxygen in the surrounding. The $\mathrm{Al}_{2} \mathrm{O}_{3}$ layer provides thermal insulation to the cutting tool which protects the tool from wearing out, thus extending its tool life. Apart from this, the TiAlN coating also increases the wear resistance of the cutting edge $[6,18,27-$ 29]. Due to an increase in tool wear, the tool radius increased from $5 \mu \mathrm{m}$ to $11 \mu \mathrm{m}$ for the TiAlN coated micro-tool and $5 \mu \mathrm{m}$ to $21 \mu \mathrm{m}$ for the uncoated micro-tool for $300 \mathrm{~mm}$ length of cut. The defects

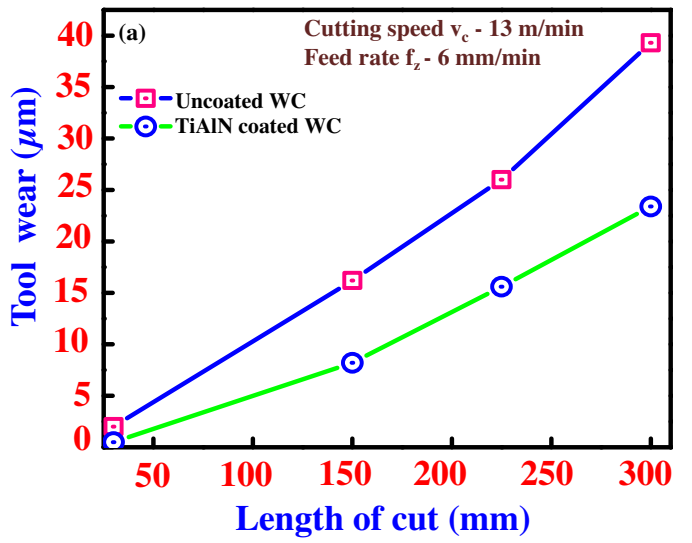

Fig. 4. Growth of tool wear with machining length for both TiAlN coated and uncoated tools. observed on a micro-end mill at the end of the machining operation are shown in Fig. 5(a) and (b). Significant edge chipping and rounding of the tool tip were observed in case of uncoated tools as compared to coated ones. This is due to the high work load on the tool tip which subsequently generates heat during machining. As a consequence, the workpiece material melts and adheres to the micro-tool, thus damaging the tool edge and affecting the overall quality of the tool tip [30-32]. In case of TiAlN coated micro-tools, mild abrasion of the coating at the cutting edges and minor delamination of the coating is observed after machining a length of $300 \mathrm{~mm}$, as shown in Fig. 5(b). However, these coated tools were still found to be suitable for further machining. The poor thermal conductivity of the workpiece material results in a high temperature closer to the interface separating the tool and the workpiece. The higher wear on uncoated micro-tools was a direct outcome of this fact. A better surface finish was produced when operating with coated microtools since the protective layer reduces the heat and the friction produced during micro-milling [33,34].

\section{Analysis of burr formation and slot geometry}

Fig. 6(a)-(d) show the FESEM images of the slots at a cutting length of $30 \mathrm{~mm}$ and $300 \mathrm{~mm}$ using uncoated and TiAlN coated micro-tools. It can be clearly seen that a large top burr is present when using uncoated micro-tools as compared to TiAlN coated micro-tools. As the machining length increases from $30 \mathrm{~mm}$ to $300 \mathrm{~mm}$, a severely damaged cutting zone was obtained while using uncoated micro-tool (Fig. 6(b)). However, the formation of burrs was found to be less when machined using a TiAlN coated micro-tool for the same machining length (Fig. 6(d)). This is a direct outcome of the increase in tool wear with cutting length for a machining operation. Fig. 6(e) shows a significant improvement in the size of burr height when a TiAlN coated micro-tool is used as compared to the uncoated tool. In addition, burr size increases with cutting length which is attributed to the increase in cutting edge radius. It can also be deduced that burr height shows an approximate linear variation with machining length in case of uncoated micro-tools [35,36]. 

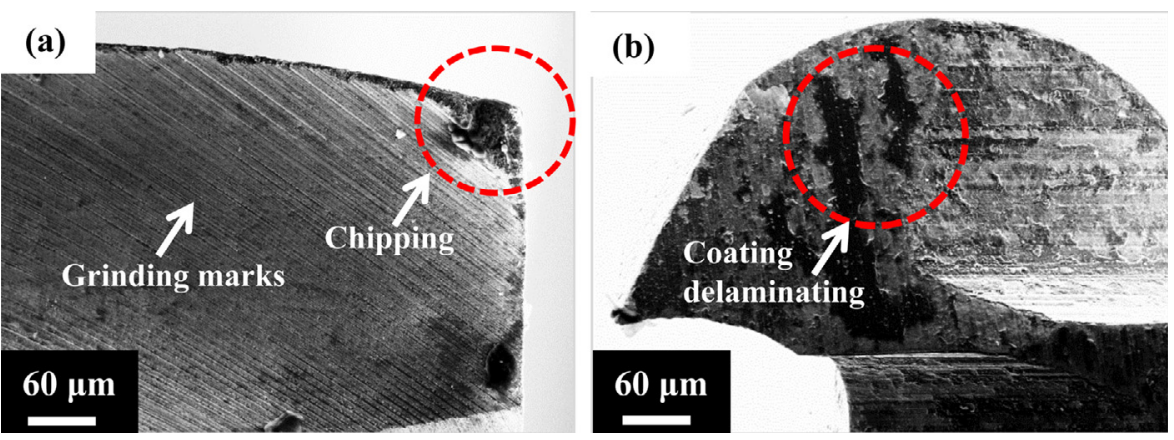

Fig. 5. Various defects formed on: (a) uncoated and (b) TiAlN coated micro-end mill after machining a length of $300 \mathrm{~mm}$.
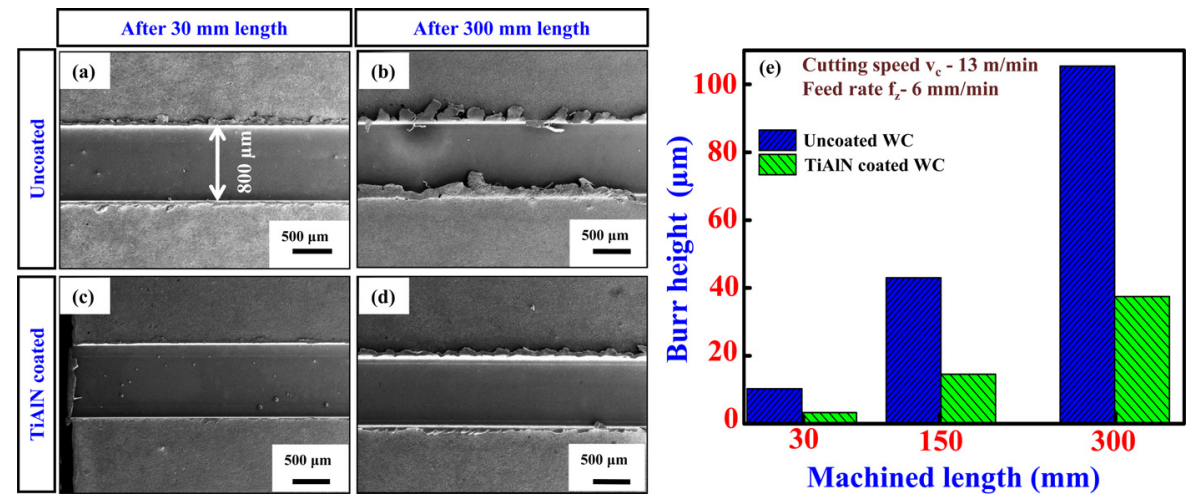

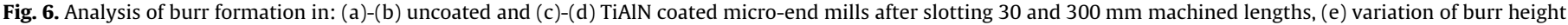
with machining length.

As compared to burrs, slot geometry showed a strong correlation with machining length. In order to study this variation, the width of the top and bottom surfaces of the micro-channels were analyzed. Fig. 7 shows the effect of tool wear-out on the size of the machined slot. It was noticed that the size of the machined slots were influenced by the progressive flank wear and corner wear of the micro-end mill. This causes a change in the width of the slot being machined as can be seen from Fig. 7(a) and (c). Slot geometry is also influenced by the steady wear acclimatized on the micro-tool with machining length. Fig. 7(b) and (d) shows the variation in burr height of uncoated and coated tools after machining a length of $300 \mathrm{~mm}$. Due to an increase in tool wear, the cutting edge radius of the micro-tool increases significantly and consequently affects the shape of the machined slot, thus leading to intense burr formation. This observation is perceptible in case of an uncoated micro-tool [24,37]. As a result of this tool edge deterioration, the width of the slot decreases from its top surface to its bottom surface [38]. This can be seen in Fig. 7(e)
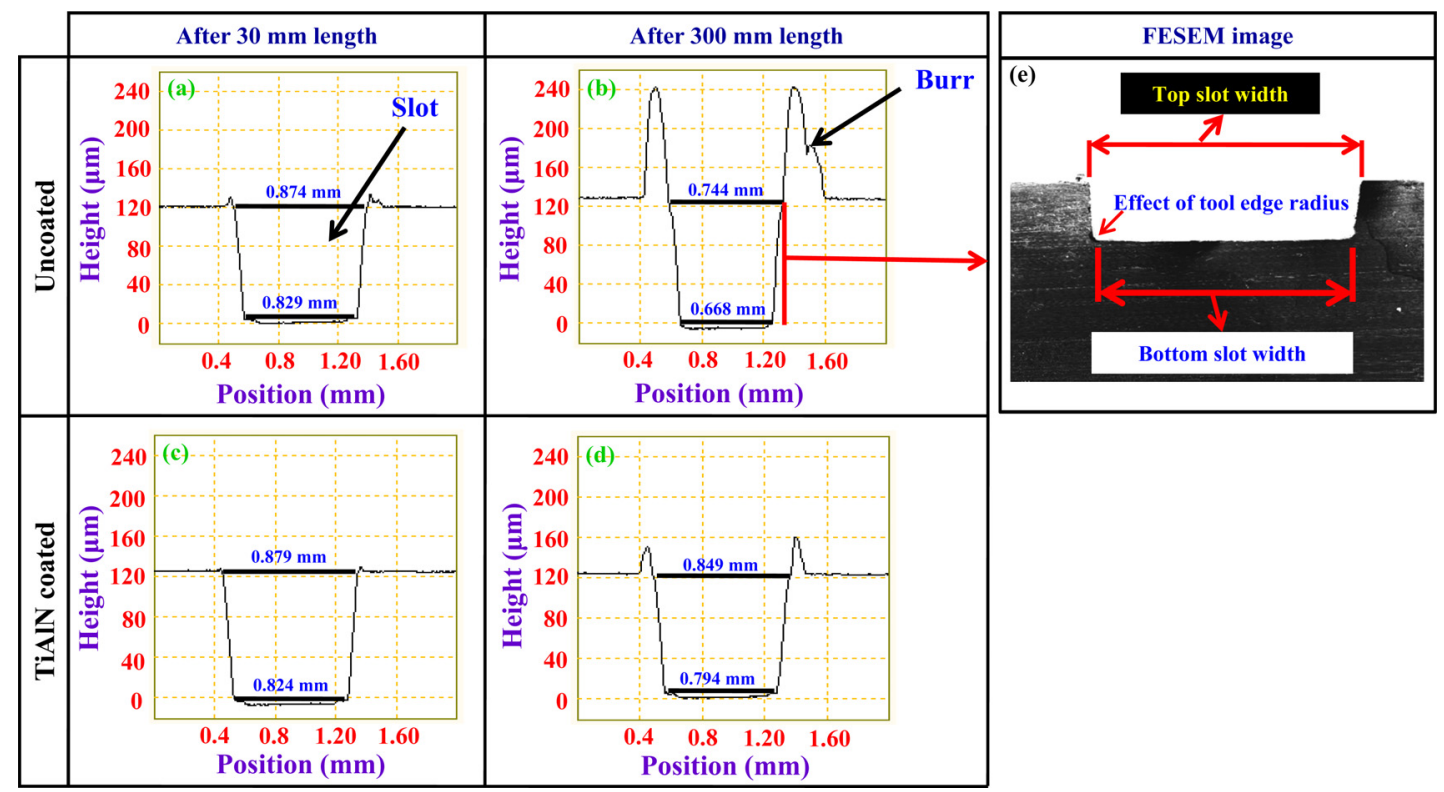

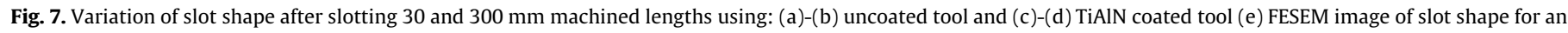
uncoated tool after $300 \mathrm{~mm}$ machined length. 

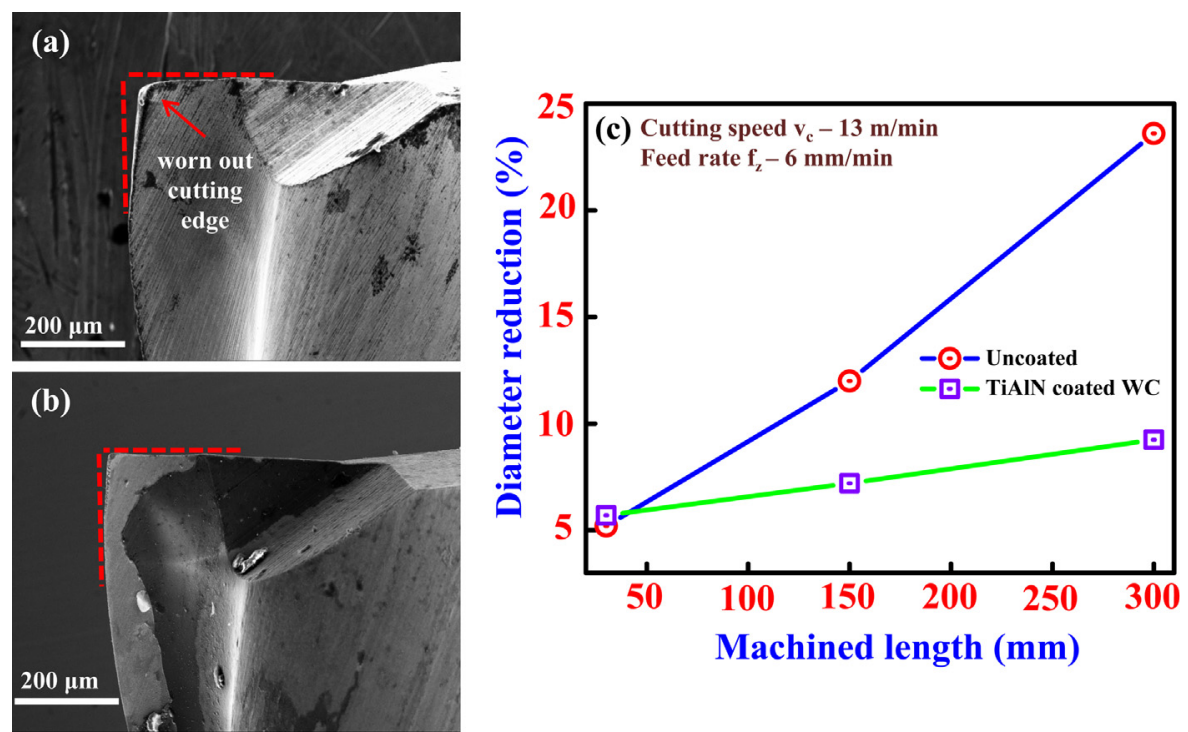

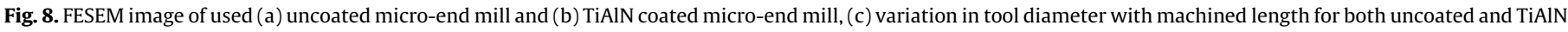
coated micro-end mill.

which shows the change in original and machined slot size for uncoated micro-tools. Coated tools show little deviation in slot width with machining length as can be seen in Fig. 7(c) and (d).

The surface integrity of the machined slots can also be ascertained qualitatively by measuring the variation in the diameter of the micro-tool. Fig. 8(a) and (b) shows the FESEM image of the uncoated and TiAlN coated micro-end mill after machining a length of $300 \mathrm{~mm}$ respectively. The decrease in diameter in case of an uncoated micro-tool was found to be higher than the coated micro-tool. The percentage decrease in tool diameter with machining length for both uncoated and coated micro-mills is shown in Fig. 8(c). It can be noted that TiAlN coated micro-tools show a lesser percentage reduction in diameter as compared to uncoated tools. This observation can be attributed due to the high hardness of TiAlN coated micro-tools and the lower coefficient of friction (approximately equal to 0.6) between the workpiece surface and the micro-tool $[18,29]$. In contrast to this, accelerated tool wear was observed in case of uncoated microtools due to the low hardness value $[21,39,40]$.

\section{Study of surface roughness}

In any metal cutting process, surface roughness depends on feed rate, cutting speed and tool radius. Fig. 9(a) shows the variation in surface roughness with feed rate at different cutting speeds for an uncoated micro-tool. A steady increase in surface roughness could be observed for various feed rates at cutting speeds of $15 \mathrm{~m} / \mathrm{min}$ and $18 \mathrm{~m} / \mathrm{min}$. However, inconclusive results
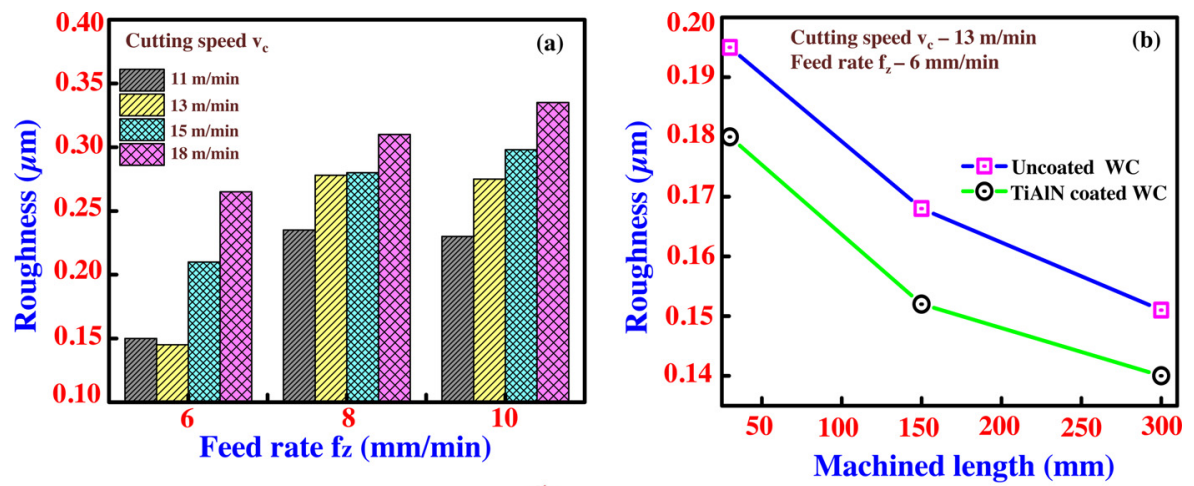

(c)

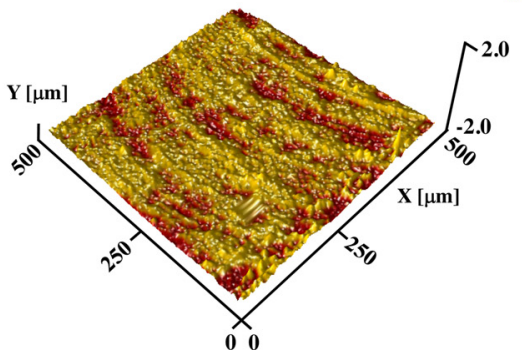

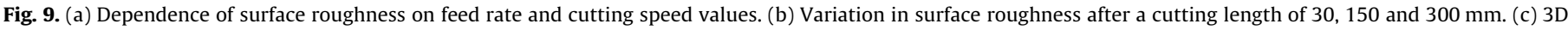
topographic image of the machined surface after a cutting length of $300 \mathrm{~mm}$ using TiAlN coated micro-tools. 
were drawn when machining at other speeds. This behaviour may possibly be attributed to the softening of the workpiece material and subsequent adhesion to the tool surface which occurs in the interface separating the tool and the workpiece at high temperatures [41]. It is also hypothesized that machining at higher speeds using an uncoated tool causes higher surface roughness due to the increased rubbing action between the hard abrasive particles of the tool surface and the workpiece material. The variation in surface roughness with machining length for both uncoated and coated tools at a cutting speed of $13 \mathrm{~m} / \mathrm{min}$ and feed rate of $6 \mathrm{~mm} / \mathrm{min}$ is shown in Fig. 9(b). It can be seen that the surface roughness for an uncoated carbide micro-tool is higher than that of the TiAlN coated micro-tool. The surface finish at the beginning of the cutting process for a coated and uncoated tool was measured to be $0.178 \mu \mathrm{m}$ and $0.195 \mu \mathrm{m}$ respectively. However, with an increase in machining length, smoother surfaces were obtained. Uncoated micro-tools produced a surface roughness of $0.151 \mu \mathrm{m}$ as compared to TiAlN-coated micro-tools which showed a roughness value of $0.139 \mu \mathrm{m}$. However, as the machining length increases to $300 \mathrm{~mm}$, a less rough surface was obtained as compared to a machining length of $30 \mathrm{~mm}$ as shown in Fig. 9(c). This is in agreement to literature results which report that a TiAlN coated micro-tool produces a better surface finish compared an uncoated tool. This may perhaps be due to the increase in the nose edge radius of the micro-tool as a result of the coating $[41,42]$.

\section{Conclusions}

The performance of a TiAlN-coated tungsten carbide was studied by comparing its machining characteristics to an uncoated tool in the micro-end milling of Nimonic 75 superalloy. The cutting performance was determined with respect to tool wear, slot geometry, burr formation and surface roughness. The findings obtained are as follows:

1. The predominant mode of failure of the cutting tool was through flank wear and chipping at the tip and edge of the tool. However, coating the micro-tool with TiAlN increased the resistance of the cutting tool to wear significantly. In this context, the reduction of tool diameter, depending on wear, was seen to be less for the TiAlN-coated tool.

2. Flank wear increased at higher cutting speeds and feed rates for both uncoated and coated micro-tools. The uncoated tool was severely damaged at cutting speeds of $15 \mathrm{~m} / \mathrm{min}$ and $18 \mathrm{~m} / \mathrm{min}$, with respective feed rates at $8 \mathrm{~mm} / \mathrm{min}$ and $10 \mathrm{~mm} / \mathrm{min}$.

3. At the beginning of the cutting process, there was no significant difference between the burrs obtained with uncoated and TiAlN coated micro-tools. However, increasing the cutting distance causes the burrs to increase for an uncoated tool. TiAlN-coated micro-tools exhibited a superior performance than uncoated tools in this regard.

4. The deviations in dimensions and surface quality of the slotted grooves were explained by critical observations such as tool wear and tool diameter reduction.

5. TiAlN coated tungsten carbide micro-tools exhibited superior performance as compared to their uncoated counterparts with regard to tool wear and surface integrity.

\section{Acknowledgements}

This work was supported by CSIR - Networked Projects (ESC 0101 and ESC 0112). Thanks are due to Mr. Siju John and Mr. Jakeer Khan for their help in giving relevant inputs. Dr. Naga Hanumaiah and Dr. S. S. Joshi are thanked for stimulating discussions of the results presented in this article.

\section{References}

[1] Venkatesh, V., Swain, N., Srinivas, G., Kumar, P., Barshilia, H., 2016, Review on the Machining Characteristics and Research Prospects of Conventional Microscale Machining Operations, Materials and Manufacturing Processes, . http:// dx.doi.org/10.1080/10426914.2016.1151045.

[2] Mouritz, A.P., 2012, Introduction to Aerospace Materials, Woodhead Publishing Ltd., Cambridge.

[3] Ezugwu, E.O., Bonney, J., Yamane, Y., 2003, An Overview of the Machinability of Aeroengine Alloys, Journal of Materials Processing Technology, 134:233-253.

[4] Choudhury, I.A., El-Baradie, M.A., 1998, Machinability of Nickel-Base Super Alloys: A General Review, Journal of Materials Processing Technology, $77: 278-284$.

[5] Ezugwu, E.O., Wang, Z.M., Machado, A.R., 1999, The Machinability of Nickel-based Alloys: A Review, Journal of Materials Processing Technology, $86: 1-16$.

[6] Dudzinski, D., Devillez, A Moufki, A Larrouquere, D Zerrouki, V., Vigneau, J. 2004, A review of Developments Towards Dry and High Speed Machining of Inconel 718 Alloy, International Journal of Machine Tools and Manufacture, 44:439-456.

[7] Jawaid, A., Koksal, S., Sharif, S., 2001, Cutting Performance and Wear Characteristics of PVD Coated and Uncoated Carbide Tools in Face Milling Inconel 718 Aerospace Alloy, Journal of Materials Processing Technology, 116:2-9.

[8] Ezugwu, E.O., 2005, Key Improvements in the Machining of Difficult-to-Cut Aerospace Superalloys, International Journal of Machine Tools and Manufacture, 45:1353-1367.

[9] Parmar, K.V., Patel, R.I., 2014, Current Research Trends in Micro Electrical Discharge Machining: A Review, IJITR, 2:717-721.

[10] Okasha, M.M., Mativenga, P.T., Driver, N., Li, L., 2010, Sequential Laser and Mechanical Micro-Drilling of Ni Superalloy for Aerospace Application, CIRP Annals - Manufacturing Technology, 59:199-202.

[11] Cheong, M.S., Cho, D-W., Ehmann, K.F., 1999, Identification and Control for Micro-Drilling Productivity Enhancement, International Journal of Machine Tools and Manufacture, 39:1539-1561.

[12] Chae, J., Park, S.S., Freiheit, T., 2006, Investigation of Micro-Cutting Operations, International Journal of Machine Tools and Manufacture, 46: 313-332.

[13] Imran, M., Mativenga, P.T., Kannan, S., Novovic, D., 2008, An Experimental Investigation of Deep-Hole Microdrilling Capability for a Nickel-based Superalloy, Journal of Engineering Manufacture, 222:1589-1596.

[14] Thakur, D.G., Ramamoorthy, B., Vijayaraghavan, L., 2012, Some Investigations on High Speed Dry machining of Aerospace Material Inconel 718 Using Multicoated Carbide Inserts, Materials and Manufacturing Processes, 27:1066-1072.

[15] Ducros, C., Benevent, V., Sanchette, F., 2003, Deposition, Characterization and Machining Performance of Multilayer PVD Coatings on Cemented Carbide Cutting Tools, Surface and Coatings Technology, 163-164:681-688.

[16] Prengel, H.G., Jindal, P.C., Wendt, K.H., Santhanam, A.T., Hegde, P.L., Penich, R.M., 2001, A New Class of High Performance PVD Coatings for Carbide Cutting Tools, Surface and Coatings Technology, 139:25-34.

[17] Ucun, I., Aslantas, K., Bedir, F., 2013, An Experimental Investigation of the Effect of Coating Material on Tool Wear in Micromilling of Inconel 718 Superalloy, Wear, 300:8-19.

[18] Barshilia, H.C., Yogesh, K., Rajam, K.S., 2009, Deposition of TiAlN Coatings using Reactive Bipolar-Pulsed Direct Current Unbalanced Magnetron Sputtering, Vacuum, 83:427-434.

[19] Gatto, A., Iuliano, L., 1997, Advanced Coated Ceramic Tools for Machining Superalloys, International Journal of Machine Tools and Manufacture, 37:591-605.

[20] Ucun, I., Aslantas, K., Gokce, B., Bedir, F., 2014, Effect of Tool Coating Materials on Surface Roughness in Micromachining of Inconel 718 Super Alloy, Proceedings of the Institution of Mechanical Engineers Part B: Journal of Engineering Manufacture, 228:1550-1562.

[21] Kuram, E., Ozcelik, B., 2015, Optimization of Machining Parameters During Micro-Milling of Ti6Al4V Titanium Alloy and Inconel 718 Materials using Taguchi Method, Proceedings of the Institution of Mechanical Engineers Part B: Journal of Engineering Manufacture, 1-15

[22] Ucun, I., Aslantas, K., Bedir, F., 2015, The Performance of DLC-Coated and Uncoated Ultra-Fine Carbide Tools in Micromilling of Inconel 718, Precision Engineering, 4:135-144

[23] LoApez de lacalle, L.N., PeArez, J., Llorente, J.I., SaAnchez, J.A., 2000, Advanced Cutting Conditions for the Milling of Aeronautical Alloys, Journal of Materials Processing Technology, 100:1-11.

[24] Zhu, D., Zhang, X., Ding, H., 2013, Tool Wear Characteristics in Machining of Nickel-based Superalloys, International Journal of Machine Tools and Manufacture, 64:60-77.

[25] Bhatt, A., Attia, H., Vargas, R., Thomson, V., 2010, Wear Mechanisms of WC Coated and Uncoated Tools in Finish Turning of Inconel 718, Tribology International, 43:1113-1121.

[26] Wu, T., 2012, Tooling Performance in Micro Milling: Modelling, Simulation and Experimental Study, (PhD thesis), Brunel University.

[27] Altin, A., Nalbant, M., Taskesen, A., 2007, The Effects of Cutting Speed on Tool Wear and Tool Life When Machining Inconel 718 with Ceramic Tools, Materials \& Design, 28:2518-2522. 
[28] Cselle, T., Barimani, A., 1995, Today's Applications and Future Developments of Coatings for Drills and Rotating Cutting Tools, Surface and Coatings Technology, 76-77:712-718.

[29] Kutschej, K., Mayrhofer, P.H., Kathrein, M., Polcik, P., Mitterer, C., 2004, A New Low-Friction Concept for Ti1xAlxN Based Coatings in High-Temperature Applications, Surface and Coatings Technology, 188-189:358-363.

[30] Sharman, A., Dewes, R.C., Aspinwall, D.K., 2001, Tool Life When High Speed Ball Nose End Milling Inconel $718^{\mathrm{TM}}$, Journal of Materials Processing Technology, 118:29-35.

[31] Liao, Y.S., Lin, H.M., Wang, J.H., 2008, Behaviors of End Milling Inconel 718 Superalloy by Cemented Carbide Tools, Journal of Materials Processing Technology, 201:460-465.

[32] Chang, L., Chengzu, R., Guofeng, W., Yinwei, Y., Lu, Z., 2015, Study on Surface Defects in Milling Inconel 718 Super Alloy, Journal of Mechanical Science and Technology, 29:1723-1730.

[33] Akhtar, W., Sun, J., Sun, P., Chen, W., Saleem, Z., 2014, Tool Wear Mechanisms in the Machining of Nickel based Super-Alloys: A Review, Frontiers of Mechanical Engineering, 9:106-119.

[34] Hao, Z., Gao, D., Fan, Y., Han, R., 2011, New Observations on Tool Wear Mechanism in Dry Machining Inconel718, International Journal of Machine Tools and Manufacture, 51:973-979.

[35] Lekkala, R., Bajpai, V., Singh, R.K., Joshi, S.S., 2011, Characterization and Modeling of Burr Formation in Micro-End Milling, Precision Engineering, 35:625-637.
[36] Schueler, G.M., Engmann, J., Marx, T., Haberland, R., Aurich, J.C., 2010, Burr Formation and Surface Characteristics in Micro-End Milling of Titanium Alloys, Springer-Verlag Berlin Heidelberg.

[37] Monroy-Vázquez, K.P., Attanasio, A., Ceretti, E., Siller, H.R., Hendrichs-Troeglen, N.J., Giardini, C., 2013, Evaluation of Superficial and Dimensional Quality Features in Metallic Micro-channels Manufactured by Micro-End-Milling, Materials, 6:1434-1451.

[38] Pratap, T., Patra, K., 2014, Machining of Microchannels using Micromilling Process, International Colloquium on Materials, Manufacturing and Metrology, Indian Institute of Technology Madras.

[39] Li, H., Lai, X., Li, C., Feng, J., Ni, J., 2008, Modelling and Experimental Analysis of the Effects of Tool Wear, Minimum Chip Thickness and Micro Tool Geometry on the Surface Roughness in Micro-End-Milling, Journal of Micromechanics and Microengineering, 18:025006.

[40] Kong, X., Yang, L., Zhang, H., Zhou, K., Wang, Y., 2014, Cutting Performance and Coated Tool Wear Mechanisms in Laser-Assisted Milling K24 Nickel-based Superalloy, International Journal of Advanced Manufacturing Technology, 77:2151-2163.

[41] Ulutan, D., Ozel, T., 2011, Machining Induced Surface Integrity in Titanium and Nickel Alloys: A Review, International Journal of Machine Tools and Manufacture, 51:250-280.

[42] Lee, K., Dornfeld, D.A., 2004, A Study of Surface Roughness in the Micro-EndMilling Process, Laboratory for Manufacturing and Sustainability. 